\title{
Dental and Dental Hygiene Students' Career Choice Motivations in 2009-17: A Mixed Methods Approach
}

\begin{abstract}
Muneeb A. Shaikh, Marita R. Inglehart
Abstract: The aims of this study were to explore career choice motivations of dental and dental hygiene students and whether their motivations differed from each other, whether their motivations changed from 2009 to 2017, and whether these motivations were affected by students' age when they decided on their career or by having a spouse/partner or family member in dentistry/ dental hygiene. A total of 959 incoming dental students and 270 incoming dental hygiene students at one U.S. university in 2009-17 were invited to participate in the study. Of those invited, 783 dental students (response rate 82\%) and 256 dental hygiene students (response rate 95\%) completed the paper and pencil surveys. Two independent raters coded the open-ended responses concerning career choice motivations ( $88 \%$ consistency). Overall, the most frequent motivations for the two groups combined were wanting to help others $(44 \%)$ and wanting a profession in the health care field $(31 \%)$; the least frequent motivation was business-related reasons ( $9 \%$ ). The dental students were more likely than the dental hygiene students to choose their profession because of wanting to help others $(47 \%$ vs. $36 \%$; $\mathrm{p}=0.001)$, human interaction aspects $(23 \% \mathrm{vs.} 11 \%$; $\mathrm{p}<0.001)$, and hands-on aspects $(22 \%$ vs. $4 \% ; \mathrm{p}<0.001)$. The dental hygiene students were more likely than the dental students to be motivated by wanting a profession in the health care field $(46 \%$ vs. $26 \%$; p $<0.001)$ and own dental experiences $(22 \%$ vs. $12 \%$; $<<0.001)$. The more recently the dental students enrolled, the more likely they were to be motivated by wanting to help others $(\mathrm{r}=0.15 ; \mathrm{p}<0.001)$ and the less by being inspired by others $(\mathrm{r}=-0.15 ; \mathrm{p}<0.001)$. Having a spouse/partner made dental students less motivated by wanting to help others and more by science-related motivations. These findings provided insights into the dental and hygiene students' career motivations and the factors that affect them. This information could contribute to more effective recruitment strategies.
\end{abstract}

Muneeb A. Shaikh is Research Assistant, Department of Periodontology and Oral Medicine, School of Dentistry, University of Michigan; and Marita R. Inglehart, Dr phil habil, is Professor of Dentistry, Department of Periodontology and Oral Medicine, School of Dentistry and Adjunct Professor of Psychology, Department of Psychology, College of Literature, Science of Arts, University of Michigan. Direct correspondence to Dr. Marita R. Inglehart, Department of Periodontics and Oral Medicine, School of Dentistry, University of Michigan, 1011 N. University Street, Ann Arbor, MI 48109-1078; 734-763-8073; mri@umich.edu.

Keywords: dental education, dental students, dental hygiene education, dental hygiene students, career choice, motivation, aspirations, career

Submitted for publication 11/20/17; accepted 2/21/18

doi: 10.21815/JDE.018.079

$\mathrm{T}$ he 2017 U.S. News \& World Report list of the 100 best jobs in the U.S. ranked dentistry as the top profession. ${ }^{1}$ Another recently published survey concerning the ten best jobs for the next decade ranked dental hygiene as the seventh best job. ${ }^{2}$ These positive rankings might motivate high school and college students to consider these careers. However, it is also of interest which other career considerations may have motivated dental and dental hygiene students to enter their professions.

Research on the reasons why students chose dentistry as their career date back to a publication by More and Kohn in $1960 .^{3}$ These authors found that occupational motivations for dentistry were the prestige of the profession, financial earnings, human service, autonomy, and the relevance of manual skills. Although each of these factors was found to be a motivating feature, the authors suggested that the opportunity for autonomy tied together these motivations. Additional research on the topic was published in the late 1990s when the focus shifted from not only identifying the factors but grouping them into categories, such as personal vs. situational motivations. ${ }^{4-6}$ Cohen and Coburn analyzed the relevance of various career choice reasons and found that the autonomy aspects of dentistry were no longer at the forefront of reasons why students wanted to become dentists. ${ }^{6}$ In the early 2000 s, additional research focused on identifying why students entered the field of dentistry. ${ }^{7-10}$ In those studies, students' motivations 
began to shift from materialistic to post-materialistic reasons, such as having favorable hours, and increasing numbers of students mentioned a desire for working with people. These studies also began to explore whether students' characteristics such as gender and race affected their career choices. Scarbecz and Ross found that race played a role in motivations and that, compared to men, women were more likely to enter dentistry because they wanted to help people. ${ }^{9}$ Research in the current decade found that factors such as financial stability and people-oriented work were more dominant themes among motivations for entering dentistry. ${ }^{11-21}$

Over the past three decades, research also focused on analyzing dental hygiene students' career choice motivations. In 1989, Carr reported that the primary career motivation for dental hygiene students was being inspired by others. ${ }^{22} \mathrm{~A}$ few other studies in the early 1990s also found this factor to be an important motivation. ${ }^{23-25}$ More recently, research found that dental hygiene students were choosing their career because of the lifestyle, patient interactions, their own dental experiences, and wanting to help others. ${ }^{26-28}$

In addition to analyzing dental and dental hygiene students' career motivations separately, it could also be interesting to explore how the students in these two career tracks differ in their career choice motivations. Knevel et al. explored this question in 2015 in Nepal. ${ }^{15}$ They found that dental students were more likely to be motivated to enter their field because of flexible working hours than were dental hygiene students and that dental hygiene students were more likely to come from a lower socioeconomic background than dental students. However, no study to date has explored whether there were differences in U.S. dental vs. dental hygiene students' career motivations. In addition, no study so far has explored dental vs. dental hygiene students' career motivations over the course of time in one academic institution.

Three additional factors may play a role for dental versus dental hygiene students' career motivations. The first factor is whether these students had a family member in dentistry or in dental hygiene. While many studies have explored whether dental students were inspired by others to choose dentistry as a career, ${ }^{14-16,18,20,29-33}$ or whether dental hygiene students were inspired by others to choose dental hygiene as their career, ${ }^{22-27}$ no research so far had explored whether having a family member in dentistry or dental hygiene would play a role for the students' decision making process. A second additional factor is whether having a spouse or partner affects dental and dental hygiene students' career choices. The age at which students make a career decision is a final factor possibly related to different career choice motivations. Based on these considerations, the aims of this study were to explore career choice motivations of dental and dental hygiene students and whether their motivations differed from each other, whether their motivations changed from 2009 to 2017, and whether these motivations were affected by students' age when they decided on their career or by having a spouse/partner or family member in dentistry/dental hygiene.

\section{Methods}

This study was determined to be exempt from Institutional Review Board (IRB) oversight by the Health Sciences and Behavioral Sciences IRB at the University of Michigan on June 23, 2017 (\#HUM00132711). A total of 959 incoming dental students and 270 incoming dental hygiene students at the University of Michigan in 2009-17 were invited to participate in this mixed-methods study. In those years, first-year dental and dental hygiene students were informed about this research at the end of regularly scheduled orientation sessions and were invited to volunteer their responses to an anonymous survey. If they agreed to participate, they received a one-page paper and pencil survey; they returned their responses anonymously to the research team.

We developed the one-page survey with the goal of gaining a better understanding of the career choice motivations of incoming dental and dental hygiene students and the factors that may affect these motivations. The survey asked students the open-ended question: "Why do you want to become a dentist/dental hygienist?" A qualitative analysis of their open-ended responses allowed us to comprehensively explore the range of reasons that motivated these students. In addition, closed-ended questions asked the respondents how old they were when they decided on this career, whether they had a spouse/ partner, and whether they had a family member in dentistry/dental hygiene. Including these questions provided the opportunity to explore whether these three factors affected career choice considerations.

The data were entered into SPSS, Version 22 (IBM Corp., Armonk, NY, USA). Two independent coders coded the open-ended responses to the question "Why do you want to become a dentist/dental hygienist?" Based on a literature review, ${ }^{3-27}$ the inde- 
pendent coders started with some overarching coding categories such as wanting to help others, being inspired by others, business-related considerations, and lifestyle-related considerations. However, based on the students' responses, additional categories were added such as hands-on aspects of the profession, science-related considerations, wanting a profession in the health care field, and own dental experiencesresulting in ten major coding categories. Descriptive statistics (frequencies, percentages, and means) were computed to provide an overview of the responses. Inferential statistics were used to compare responses of subgroups of respondents such as the responses of dental vs. dental hygiene students or responses of students with vs. without a family member in dentistry/dental hygiene. Comparisons of frequencies of responses were analyzed with chi square tests and comparisons of average responses with independent sample t-tests. Pearson correlation coefficients were computed to determine the relationships between the frequencies of career choices and the year in which the respondents entered their program. A p-value of $\mathrm{p}<0.05$ was used as the level of significance.

\section{Results}

Of the 959 dental students and 270 dental hygiene students invited to participate, 783 dental and 256 dental hygiene students responded to the survey (response rates $82 \%$ and $95 \%$, respectively; overall $85 \%$ ). Table 1 shows the number of responses for each group in each year.

Table 2 shows the number of responses concerning these incoming students' career choice moti- vations. The two independent coders started with the same transcript of the open-ended answers to the question "Why do you want to become a dentist/ dental hygienist?" Rater 1 coded 2,094 responses, and Rater 2 coded 2,126 responses; 1,851 statements were rated consistently by the two raters. The most frequently mentioned motivation was wanting to help others (Rater 1: $\mathrm{N}=548$; Rater 2: $\mathrm{N}=546$ ). The second most frequently used motivation was wanting a profession in the health care field (Rater 1: $\mathrm{N}=305$; Rater 2: $\mathrm{N}=312$ ). Hands-on aspects of the profession motivated 222 students in each of the two programs. Motivations derived from the human interaction aspect of the profession (Rater 1: $\mathrm{N}=188$; Rater 2: $\mathrm{N}=231$ ), being inspired by others (Rater 1 : $\mathrm{N}=203$; Rater 2: $\mathrm{N}=207$ ), and lifestyle-related considerations (Rater 1: $\mathrm{N}=171$; Rater 2: $\mathrm{N}=166$ ) were also identified quite frequently. Roughly 145 students in each of the two groups reported being inspired by their own dental experiences, and slightly over 100 reported science-related considerations. About 100 students in each group reported choosing their careers because of wanting a meaningful career or for businessrelated reasons. The two raters coded $88 \%$ of the responses consistently, which is an acceptable rate of interrater consistency.

We also compared the percentages of dental vs. dental hygiene responses in each of the ten major categories. The two groups differed significantly on eight of the ten categories (Table 3 ). A higher percentage of dental students than dental hygiene students were motivated by wanting to help others ( $47 \%$ vs. $36 \% ; \mathrm{p}<0.001)$, hands-on aspects of the profession ( $22 \%$ vs. $4 \%$; $<0.001)$, human interaction aspects of the profession $(23 \%$ vs. $11 \%$; $<<0.001)$, lifestyle-

Table 1. Number of all dental and dental hygiene students and survey respondents by year, 2009 to 2017

\begin{tabular}{lcccccc} 
& \multicolumn{2}{c}{ Dental Students } & \multicolumn{2}{c}{ Dental Hygiene Students } & \multicolumn{2}{c}{ Total Students } \\
All & $\begin{array}{c}\text { Respondents } \\
\text { Year }\end{array}$ & $\begin{array}{c}\text { All } \\
\text { Students }\end{array}$ & $\begin{array}{c}\text { Respondents } \\
\text { (Response Rate) }\end{array}$ & Students & Response Rate) & All \\
Students & Response Rate) \\
\hline 2009 & 105 & $61(58 \%)$ & 31 & $25(81 \%)$ & 136 & $86(63 \%)$ \\
2010 & 106 & $66(62 \%)$ & 30 & $30(100 \%)$ & 136 & $96(71 \%)$ \\
2011 & 108 & $77(71 \%)$ & 35 & $32(91 \%)$ & 143 & $109(76 \%)$ \\
2012 & 104 & $87(84 \%)$ & 23 & $20(87 \%)$ & 127 & $107(84 \%)$ \\
2013 & 105 & $104(99 \%)$ & 29 & $29(100 \%)$ & 134 & $133(99 \%)$ \\
2014 & 106 & $104(98 \%)$ & 26 & $26(100 \%)$ & 132 & $130(98 \%)$ \\
2015 & 109 & $80(73 \%)$ & 32 & $32(100 \%)$ & 141 & $112(79 \%)$ \\
2016 & 107 & $97(91 \%)$ & 32 & $30(94 \%)$ & 139 & $127(91 \%)$ \\
2017 & 109 & $107(98 \%)$ & 32 & $32(100 \%)$ & 141 & $139(99 \%)$ \\
Total & 959 & $783(82 \%)$ & 270 & $256(95 \%)$ & 1229 & $1039(85 \%)$ \\
\hline
\end{tabular}


Table 2. Responses concerning career choice motivations for total respondents (dental and dental hygiene students) as coded by Rater 1 and Rater 2

\begin{tabular}{|c|c|c|c|c|c|}
\hline Motivation & $\begin{array}{c}\text { Rater } 1 \\
\mathrm{~N}=2094\end{array}$ & $\begin{array}{l}\text { Rater } 2 \\
\mathrm{~N}=2126\end{array}$ & Motivation & $\begin{array}{c}\text { Rater } 1 \\
N=2094\end{array}$ & $\begin{array}{c}\text { Rater } 2 \\
\mathrm{~N}=2126\end{array}$ \\
\hline \multicolumn{3}{|l|}{ Wanting to help others } & \multicolumn{3}{|l|}{ Lifestyle-related considerations } \\
\hline Helping others & 291 & 284 & Lifestyle & 45 & 45 \\
\hline Better serve community/underserved & 77 & 81 & Flexibility & 40 & 31 \\
\hline Create beautiful smiles & 61 & 64 & Good/stable job & 27 & 31 \\
\hline Help to reduce health care disparity & 36 & 32 & Great balance work/family & 20 & 22 \\
\hline Help others feel good & 32 & 25 & Support a family/good pay & 18 & 17 \\
\hline Improve health & 27 & 27 & Good hours & 11 & 12 \\
\hline Career of service & 22 & 28 & Respected profession & 5 & 5 \\
\hline Aid patient in diagnosis & 2 & 5 & No residency/less schooling & 3 & 2 \\
\hline Total & $548(26 \%)$ & $546(26 \%)$ & Fast-paced & 2 & 1 \\
\hline \multicolumn{3}{|c|}{ Wanting a profession in the health care field } & Total & $171(8 \%)$ & $166(8 \%)$ \\
\hline Being in health care/oral health care & 105 & 124 & Own dental experiences & & \\
\hline Love/interested in teeth & 65 & 64 & Own dental experience & 62 & 55 \\
\hline Preventive care & 33 & 28 & Good experiences with dentist & 31 & 33 \\
\hline Liked medical field & 26 & 28 & Dental assisting & 18 & 19 \\
\hline Wanted to be dentist/dentistry-related & 20 & 23 & Lot of work done on teeth & 18 & 14 \\
\hline Primary health care provider & 21 & 13 & Braces & 8 & 13 \\
\hline Health care-related opportunities & 16 & 16 & Mission trip & 7 & 8 \\
\hline Liked dental atmosphere & 14 & 12 & Volunteer & 2 & 2 \\
\hline Health care with artistic aspect & 5 & 4 & Total & $146(7 \%)$ & $144(7 \%)$ \\
\hline Total & $305(15 \%)$ & $312(15 \%)$ & Science-related considerations & & \\
\hline Hands-on aspects of profession & & & Science-related & 56 & 54 \\
\hline Work with hands & 142 & 141 & Love sciences & 42 & 43 \\
\hline Being artistic & 70 & 70 & Biology involved & 12 & 11 \\
\hline Requires precision & 10 & 7 & Continue science & 7 & 4 \\
\hline Total & $222(11 \%)$ & $(10 \%)$ & Total & $117(6 \%)$ & $112(5 \%)$ \\
\hline \multicolumn{3}{|l|}{ Human interaction aspects of profession } & \multicolumn{3}{|l|}{ Wanting a meaningful career } \\
\hline Patient relationships & 84 & 117 & Enjoy field/job/dream job & 42 & 39 \\
\hline Personal contact/human interactions & 96 & 105 & Rewarding career & 23 & 23 \\
\hline Being sociable & 8 & 9 & Meaningful career & 19 & 18 \\
\hline Total & $188(9 \%)$ & $231(11 \%)$ & Mentally challenging & 15 & 13 \\
\hline \multicolumn{3}{|l|}{ Being inspired by others } & Independence & 7 & 5 \\
\hline Inspired by family member/friend & 39 & 49 & Total & $106(5 \%)$ & $98(5 \%)$ \\
\hline Shadowing a dentist & 40 & 39 & \multicolumn{3}{|l|}{ Business-related considerations } \\
\hline Inspired by family dentist/general dentis & ist 38 & 37 & Be my own boss/have own business & 43 & 45 \\
\hline Introduced to dentistry at young age & 22 & 17 & Business aspects & 22 & 25 \\
\hline Working in practice/dental office & 20 & 19 & Education & 14 & 14 \\
\hline Inspired by orthodontist & 13 & 14 & Stepping stone & 9 & 8 \\
\hline Inspired by others & 12 & 12 & Lifelong learning & 7 & 7 \\
\hline Inspired by dental hygienist & 9 & 10 & Total & $95(5 \%)$ & $99(5 \%)$ \\
\hline Inspired by doing dental research & 7 & 7 & \multirow{4}{*}{$\begin{array}{l}\text { Number of codes } \\
\text { Number of consistent codes } \\
\text { Percentage of consistent codes }\end{array}$} & \multirow{4}{*}{$\begin{array}{l}2094 \\
1851 \\
88 \%\end{array}$} & \multirow{4}{*}{$\begin{array}{l}2126 \\
1851 \\
87 \%\end{array}$} \\
\hline Inspired by pediatric dentist & 1 & 1 & & & \\
\hline Inspired by oral surgery & $\begin{array}{l}1 \\
1\end{array}$ & $\begin{array}{l}1 \\
1\end{array}$ & & & \\
\hline $\begin{array}{l}\text { Pre-dental club } \\
\text { Total }\end{array}$ & $\begin{array}{c}1 \\
203(10 \%)\end{array}$ & $\begin{array}{c}1 \\
207(10 \%)\end{array}$ & & & \\
\hline
\end{tabular}

related considerations $(13 \%$ vs. $7 \% ; \mathrm{p}=0.002)$, science-related aspects of the profession (13\% vs. $4 \% ; \mathrm{p}<0.001)$, and business-related considerations ( $11 \%$ vs. $4 \%$; $=0.001)$. Compared to dental students, higher percentages of dental hygiene students were motivated by wanting a profession in the health care field $(26 \%$ vs. $46 \%$; $<0.001)$ and their own dental experiences $(12 \%$ vs. $22 \%$; $p<0.01)$.

In addition to exploring if there were significant differences in career choice motivations between 
Table 3. Career choice motivations of students, by percentages of total responding dental students $(\mathrm{N}=783)$ and dental hygiene students $(\mathrm{N}=\mathbf{2 5 6})$

\begin{tabular}{|c|c|c|c|}
\hline Motivation & Dental Students & Dental Hygiene Students & p-value \\
\hline Wanting to help others & $47 \%$ & $36 \%$ & 0.001 \\
\hline Wanting a profession in the health care field & $26 \%$ & $46 \%$ & $<0.001$ \\
\hline Hands-on aspects of profession & $22 \%$ & $4 \%$ & $<0.001$ \\
\hline Human interaction aspects of profession & $23 \%$ & $11 \%$ & $<0.001$ \\
\hline Being inspired by others & $15 \%$ & $19 \%$ & 0.075 \\
\hline Lifestyle-related considerations & $13 \%$ & $7 \%$ & 0.002 \\
\hline Own dental experiences & $12 \%$ & $22 \%$ & $<0.001$ \\
\hline Science-related considerations & $13 \%$ & $4 \%$ & $<0.001$ \\
\hline Wanting a meaningful career & $10 \%$ & $11 \%$ & 0.481 \\
\hline Business-related considerations & $11 \%$ & $4 \%$ & 0.001 \\
\hline
\end{tabular}

Note: Chi-square tests were used to compare the percentages of dental versus dental hygiene students' answers in each category. The percentages of responses of dental vs. dental hygiene students in each of the ten categories were computed by considering if a student had vs. did not have at least one reason in a given category. The sum of percentages in each column can total over $100 \%$ because students could have more than one motivation for choosing their profession.

the two groups, we sought to determine whether the likelihood of choosing dentistry or dental hygiene changed over the nine years from 2009 to 2017. Pearson correlation coefficients were therefore computed to determine the relationships between the year students entered their professional programs and the likelihood of having chosen one of the motivations (Table 4). The more recently dental students entered their program, the more likely they were to name wanting to help others $(r=0.15 ; \mathrm{p}<0.001)$ as a motivation and the less likely they were to report being inspired by others $(\mathrm{r}=-0.15 ; \mathrm{p}<0.001)$ and by their own dental experiences $(r=-0.10 ; p<0.01)$. For the dental hygiene students, the year of beginning their program was significantly correlated with the likelihood of wanting a profession in the health care field $(\mathrm{r}=0.12 ; \mathrm{p}<0.05)$. However, these significant correlations were relatively small and explain only a small percentage of the variance.

The results showed that having a spouse/partner may have affected the dental students' motivations in two ways (Table 5). Among the dental students, $49 \%$ without a spouse/partner reported that wanting to help others was a motivation, while only $39 \%$ with a spouse/partner reported this reason $(\mathrm{p}<0.05)$. In addition, $15 \%$ of dental students without a partner/ spouse reported being motivated by science-related motivation, while only $6 \%$ with a spouse/partner reported this type of motivation $(\mathrm{p}<0.01)$. Having a partner versus not having a partner did not make a difference for the dental hygiene students' responses.

Having a family member in dentistry or dental hygiene only made a difference in the percentages of dental students who were motivated by human interaction aspects of the profession. While $26 \%$ of the dental students with a family member in the dental or dental hygiene profession identified this career motivation, only $21 \%$ of the dental students without a family member in the profession identified this motivation $(\mathrm{p}<0.05)$.

Table 6 compares dental and dental hygiene students' average age if they responded positively versus negatively to each of the motivation categories. Dental students who chose their career because of the hands-on aspects decided at a later age to become dentists (18.34 years versus 17.35 years; $\mathrm{p}<0.05)$ than dental students who did not report this motivation. Dental students who reported being inspired by others as a motivation were on average younger when they decided to become dentists than dental students who were not motivated by others' inspiration $(16.07$ years vs. 17.82 years; $p<0.001)$. The same pattern held for the dental students who were vs. were not motivated by their own dental experiences. The students who did not report this reason were on average 17.78 years of age, while the dental students who did list this reason were on average 16.08 years of age $(p<0.001)$. The age at which dental hygiene students decided to choose their profession did not differ as a function of whether they were motivated versus not motivated by these career factors.

\section{Discussion}

This study went beyond previous research in three ways. First, while quite a number of studies have researched the career choice motivations of dental students ${ }^{3-21}$ and dental hygiene students, ${ }^{22-28}$ only one previous study had explored how dental 
Table 4. Relationships between year of entering dental school/dental hygiene program and type of reported motivation for career choice for each student type

\begin{tabular}{lcc} 
Motivation & $\begin{array}{c}\text { Year of Entering } \\
\text { Dental School }\end{array}$ & $\begin{array}{c}\text { Year of Entering } \\
\text { Dental Hygiene Program }\end{array}$ \\
\hline Wanting to help others & $0.15^{* * *}$ & -0.07 \\
Wanting a profession in the health care field & -0.01 & $0.12^{* *}$ \\
Hands-on aspects of profession & 0.03 & 0.08 \\
Human interaction aspects of profession & $0.07^{*}$ & -0.02 \\
Being inspired by others & $-0.15^{* * *}$ & 0.10 \\
Lifestyle-related considerations & -0.03 & 0.02 \\
Own dental experiences & $-0.10^{* *}$ & 0.03 \\
Science-related considerations & -0.001 & -0.07 \\
Wanting a meaningful career & -0.07 & 0.02 \\
Business-related considerations & 0.05 & 0.08 \\
${ }^{*} \mathrm{p}<0.05 ; * * \mathrm{p}<0.01 ; * * * \mathrm{p}<0.001$ & &
\end{tabular}

Table 5. Career choice motivations of students with vs. without a spouse/partner and with vs. without a family member in dentistry/dental hygiene, by percentages of total dental students $(\mathrm{N}=783)$ and dental hygiene students $(\mathrm{N}=256)$

\begin{tabular}{|c|c|c|c|c|c|}
\hline \multirow[b]{2}{*}{ Response } & \multirow[b]{2}{*}{ Student Type } & \multicolumn{2}{|c|}{$\begin{array}{l}\text { Spouse } \\
\text { or Partner }\end{array}$} & \multicolumn{2}{|c|}{$\begin{array}{l}\text { Family Member in } \\
\text { Dentistry/Dental Hygiene }\end{array}$} \\
\hline & & No & Yes & No & Yes \\
\hline \multirow[t]{2}{*}{ Percentage of } & Dental & $82 \%$ & $18 \%$ & $63 \%$ & $37 \%$ \\
\hline & Hygiene & $76 \%$ & $24 \% *$ & $70 \%$ & $30 \% *$ \\
\hline \multicolumn{6}{|l|}{ Motivated by } \\
\hline \multirow[t]{2}{*}{ Wanting to help others } & Dental & $49 \%$ & $39 \% *$ & $45 \%$ & $50 \%$ \\
\hline & Hygiene & $34 \%$ & $40 \%$ & $36 \%$ & $36 \%$ \\
\hline \multirow[t]{2}{*}{ Wanting a profession in the health care field } & Dental & $26 \%$ & $30 \%$ & $28 \%$ & $24 \%$ \\
\hline & Hygiene & $45 \%$ & $50 \%$ & $46 \%$ & $46 \%$ \\
\hline \multirow[t]{2}{*}{ Hands-on aspects of dentistry } & Dental & $24 \%$ & $18 \%$ & $22 \%$ & $23 \%$ \\
\hline & Hygiene & $4 \%$ & $3 \%$ & $3 \%$ & $5 \%$ \\
\hline \multirow[t]{2}{*}{ Human interaction aspects of profession } & Dental & $23 \%$ & $20 \%$ & $21 \%$ & $26 \% *$ \\
\hline & Hygiene & $11 \%$ & $10 \%$ & $12 \%$ & $9 \% * * *$ \\
\hline \multirow[t]{2}{*}{ Being inspired by others } & Dental & $15 \%$ & $16 \%$ & $15 \%$ & $14 \%$ \\
\hline & Hygiene & $21 \%$ & $11 \% * * *$ & $21 \%$ & $13 \%$ \\
\hline \multirow[t]{2}{*}{ Lifestyle-related considerations } & Dental & $12 \%$ & $17 \%$ & $12 \%$ & $14 \%$ \\
\hline & Hygiene & $7 \%$ & $5 \%$ & $6 \%$ & $8 \%$ \\
\hline \multirow[t]{2}{*}{ Own dental experiences } & Dental & $13 \%$ & $11 \%$ & $14 \%$ & $10 \% * * *$ \\
\hline & Hygiene & $22 \%$ & $21 \%$ & $22 \%$ & $21 \%$ \\
\hline \multirow[t]{2}{*}{ Science-related motivation } & Dental & $15 \%$ & $6 \% * *$ & $12 \%$ & $15 \%$ \\
\hline & Hygiene & $5 \%$ & $2 \%$ & $4 \%$ & $4 \%$ \\
\hline \multirow[t]{2}{*}{ Wanting a meaningful career } & Dental & $9 \%$ & $14 \%$ & $10 \%$ & $11 \%$ \\
\hline & Hygiene & $10 \%$ & $13 \%$ & $11 \%$ & $11 \%$ \\
\hline \multirow[t]{2}{*}{ Business-related reasons } & Dental & $10 \%$ & $13 \%$ & $12 \%$ & $9 \%$ \\
\hline & Hygiene & $4 \%$ & $7 \%$ & $4 \%$ & $5 \%$ \\
\hline
\end{tabular}

Note: Chi-square tests were used to compare the percentages of dental versus dental hygiene students' answers in each condition.

${ }^{*} \mathrm{p}<0.05 ;{ }^{* *} \mathrm{p}<0.01 ;{ }^{* * *} \mathrm{p}<0.001$

versus dental hygiene students' career motivations differed. ${ }^{15}$ That earlier study took place in Nepal, and a generalization of its results to the U.S. is limited due to cultural differences. The fact that the data from both dental and dental hygiene students in our study were collected in the U.S. allows a definitive comparison. Second, no previous study had looked at the question of career choice motivations in dentistry and dental hygiene over a consecutive period of time. Having data from nine consecutive cohorts provided 


\begin{tabular}{|c|c|c|c|}
\hline Motivation & $\begin{array}{l}\text { Motivation } \\
\text { No/Yes }\end{array}$ & $\begin{array}{l}\text { Dental Students' Age } \\
\qquad \mathrm{N}=783\end{array}$ & $\begin{array}{l}\text { Dental Hygiene Students' Age } \\
\qquad N=256\end{array}$ \\
\hline \multirow[t]{2}{*}{ Wanting to help others } & No & 17.62 & 18.50 \\
\hline & Yes & 17.51 & $17.33^{*}$ \\
\hline \multirow[t]{2}{*}{ Wanting a profession in the health care field } & No & 17.51 & 18.39 \\
\hline & Yes & 17.73 & 17.74 \\
\hline \multirow[t]{2}{*}{ Hands-on aspects of dentistry } & No & 17.35 & 18.13 \\
\hline & Yes & $18.34^{* *}$ & 17.10 \\
\hline \multirow[t]{2}{*}{ Human interaction aspects of dentistry } & No & 17.41 & 18.20 \\
\hline & Yes & $18.11^{*}$ & 17.15 \\
\hline \multirow[t]{2}{*}{ Being inspired by others } & No & 17.82 & 18.26 \\
\hline & Yes & $16.07^{* * *}$ & 17.35 \\
\hline \multirow[t]{2}{*}{ Lifestyle-related considerations } & No & 17.49 & 17.98 \\
\hline & Yes & 18.10 & 19.47 \\
\hline \multirow[t]{2}{*}{ Own dental experiences } & No & 17.78 & 18.16 \\
\hline & Yes & $16.08^{* * *}$ & 17.80 \\
\hline \multirow[t]{2}{*}{ Science-related motivation } & No & 17.61 & 18.14 \\
\hline & Yes & 17.26 & 16.80 \\
\hline \multirow[t]{2}{*}{ Wanting a meaningful career } & No & 17.48 & 17.99 \\
\hline & Yes & 18.38 & 18.88 \\
\hline \multirow[t]{2}{*}{ Business-related reasons } & No & 17.45 & 18.03 \\
\hline & Yes & $18.54^{*}$ & 19.36 \\
\hline
\end{tabular}

a unique opportunity to gain a better understanding of these issues. Third, quantitative research into the question of career choice motivations of dental and dental hygiene students builds on previous research and asks questions based on previous findings. Utilizing an open-ended question and collecting qualitative data in our study went beyond a quantitative approach because it allowed respondents to provide answers that had not been previously reported in quantitative research studies. The answers to the question "Why do you want to become a dentist/ dental hygienist?" were not only coded according to previously reported categories, but made it possible to identify new categories of career choice motivations. An example of a motivation many authors had identified before was to help others. Research with both dental students ${ }^{7-9,11,13-15,17,30,31,34-38}$ and dental hygiene students ${ }^{15,26,27}$ found that this motivation appeared frequently. However, the use of open-ended responses in our study enabled the emergence of previously largely neglected issues, such as wanting a profession in the health care field ${ }^{31}$ and being motivated by own dental experiences, ${ }^{26,39,40}$ as well as previously unidentified issues such as being motivated by an interest in science. Overall, ten career choice motivations were identified.
Comparison of the dental versus dental hygiene students' responses showed that the two groups differed in eight of these motivations. The dental hygiene students were more likely than the dental students to choose their career because of wanting a profession in the health care field and because of their own dental experiences. The dental students were more likely than the dental hygiene students to choose their career because they wanted to help others and due to the hands-on aspects of dentistry, the human interaction aspects, lifestyle considerations, science-related considerations, and business-related considerations. Recruiting efforts should consider these differential findings and develop comprehensive and tailored recruitment materials for both groups of students.

The fact that changes in the prevalence of certain motivations occurred over the nine-year period studied should alert recruitment and admission staffs as well as educators about the changing nature of career motivations. Changing environmental conditions such as an increasing percentage of dentists working in corporate dentistry could definitely affect career motivations in the future.

Anecdotally, it seems as if legacy cases were frequent in these dental and dental hygiene classes. 
Our data showed that $37 \%$ of the dental students and $30 \%$ of the dental hygiene students had a family member in dentistry or in dental hygiene; however, students with such family members did not differ overall in their career choice motivations from students without such family backgrounds. In the past, studies clearly showed that students chose their career because they were inspired by others in choosing dentistry ${ }^{14-16,18,20,29-33}$ or dental hygiene..$^{22-27}$ However, being inspired by others might differ from being inspired by a close family member in the profession. For example, having a parent who owns a successful dental practice and discusses the benefits of passing on this practice to a daughter or son might result in different motivational considerations then having been inspired by an orthodontist who provided treatment for a potential student. Explicitly exploring the role that having close family members in these professions played for students' career decision making was therefore of interest.

A final objective was to explore if the age at which the students made a career decision was related to the various motivations. While a previous study reported that the age at which medical students decided to enter the medical profession affected their motivation during medical school and their academic achievement, ${ }^{41}$ our study found that it played a role for only three out of the ten career choice motivations for the participating dental students.

One limitation of this study was the lack of information about the respondents' gender and race. Several studies previously explored the role of these two factors and found that race and gender did play a role in career choice motivations..$^{7-10}$ For example, they showed that the women were more likely to enter dentistry because they wanted to help people than did the men. No questions about race and gender were included in our study to ensure that students understood their answers were anonymous. If there was only one male black student in a class, for instance, anonymity would not be guaranteed if race and gender data were collected. However, future research should consider how demographic characteristics such as race, gender, age, and socioeconomic background affect career choice motivations. A second limitation was that these data were collected at only one university, limiting the generalizability of the findings. Dental hygiene students enrolled in programs at community colleges, for example, could have different motivations than the dental hygiene students included in our study. Future research should therefore explore the effect of type of program in this context.

\section{Conclusion}

Our study found that these dental and dental hygiene students entered their professional training based on one or more of ten motivations. The two most prevalent motivations were wanting to help others $(26 \%)$ and wanting a profession in the health care field (15\%). The two least prevalent motivations were wanting a meaningful career $(5 \%)$ and business-related considerations (5\%). Compared to the dental students, the dental hygiene students were more likely to have chosen their career because of wanting a profession in the health care field and their own dental experiences. The dental students were more likely than the dental hygiene students to have chosen their career because they wanted to help others and because of the hands-on aspects of dentistry, the human interaction aspects, lifestyle considerations, science-related considerations, and business-related considerations. The more recently the dental students had entered dental school, the more they were motivated by wanting to help others and the less motivated they were by being inspired by others and their own dental experiences. The more recently the dental hygiene students had begun their program, the more they were motivated by wanting a profession in a health care field. Overall, having a family member in dentistry/dental hygiene did not affect career choice motivations. However, the dental students with family members in these professions were more likely to be motivated by being inspired by human interaction aspects than students who did not have family members in these professions. All these findings can inform recruitment efforts for dental schools and dental hygiene programs.

\section{Acknowledgments}

We want to thank the University of Michigan School of Dentistry for allowing the distribution of the "Getting to Know You" surveys during the dental and dental hygiene orientations. This project was supported by Zainalabdeen Rabeah, Jocelid Carreno, Nicholas Zoppi, Nolan Wendling, and Lincoln Erickson.

\section{REFERENCES}

1. U.S. News \& World Report. The 100 best jobs of 2017. 2017. At: money.usnews.com/careers/best-jobs/rankings/ the-100-best-jobs. Accessed 20 Nov. 2017.

2. Mejia Z. These are the top 10 best and worst jobs for the future. 2017. At: www.cnbc.com/2017/09/01/these-arethe-top-10-best-and-worst-jobs-for-the-future.html. Accessed 20 Nov. 2017. 
3. More DM, Kohn N. Some motives for entering dentistry. Am J Sociol 1960;66(1):48-53.

4. Brand AA, Chikte UME, Thomas CJ. Choosing dentistry as a career: a profile of entering students (1992) to the University of Sydney, Australia. Aust Dent J 1996;41(3): 198-205.

5. Davis JEC, Sales GD. Dental and life science students: a comparison of approaches to study and course perceptions. Med Educ 1996;30:453-8.

6. Cohen R, Coburn D. Motivations for studying dentistry among first-year dental students. Med Educ 1997;11: 139-43.

7. Crossley ML, Mubarik A. A comparative investigation of dental and medical students' motivation towards career choice. Br Dent J 2002;193(8):471-3.

8. Butters JM, Winter PA. Professional motivation and career plan differences between African-American and Caucasian dental students: implication for improving workforce diversity. J Natl Med Assoc 2002;94(6):492-504.

9. Scarbecz M, Ross J. Gender differences in first-year dental students' motivation to attend dental school. J Dent Educ 2002;66(8):952-61.

10. Vigild M, Schwarz E. Characteristics and study motivation of Danish dental students in longitudinal perspective. Eur J Dent Educ 2001;5:127-33.

11. Aggarwal A, Mehta S, Gupta D, et al. Dental students' motivations and perceptions of dental professional career in India. J Dent Educ 2012;76(11):1532-9.

12. Belsi A, Asimakopoulou K, Donaldson N, Gallagher J. Motivation to study dental professions in one London dental institute. Eur J Dent Educ 2014;18:24-30.

13. Lalloo R, Evans JL, Johnson NW. Dental students' reflections on clinical placement in a rural and indigenous community in Australia. J Dent Educ 2013;77(9):1193-201.

14. Toit JD, Jain S, Montalli V, Govender U. Dental students' motivation for their career choice: an international investigative report. J Dent Educ 2014;78(4):605-13.

15. Knevel RJM, Gussy MG, Farmer J, Karimi L. Nepalese dental hygiene and dental students' career choice motivation and plans after graduation: a descriptive crosssectional comparison. BMC Med Educ 2015;15(219).

16. Halawany HS. Career motivations, perceptions of the future of dentistry, and preferred dental specialties among Saudi dental students. Open Dent J 2014;8:129-35.

17. Gardner SP, Roberts-Thomson KF. The effect of a change in selection procedures on students' motivation to study dentistry. Aust Dent J 2014;59:2-8.

18. Ferraz dos Santos B, Nicolau B, Muller K, et al. Brazilian dental students' intentions and motivation towards their professional career. J Dent Educ 2013;77(3):337-44.

19. Banabilh SM. Career decisions of undergraduate dental students at the University of Science and Technology, Yemen. J Dent Educ 2013;77(3):331-6.

20. Baharvand M, Moghaddam EJ, Pourretemad H, Alavi K. Attitudes of Iranian dental students toward their future careers: an exploratory study. J Dent Educ 2011;75(11): 1489-95.

21. Avramova N, Yaneva K, Bonev B. First-year dental students' motivation and attitudes for choosing the dental profession. Acta Medica Academica 2014;43:113-21.

22. Carr S. Factors influencing the career selection of first-year dental hygiene students. J Dent Hyg 1989;63(6):268-71.
23. Wassel JR. Factors influencing the selection of dental hygiene as a profession. J Dent Hyg 1992;66(2):81-8.

24. DeVore PL, Whitacre HL, Cox SS. Selection of dental hygiene as a career: associate degree students compared with baccalaureate students. Focus Ohio Dent 1993;67(1): 2-3,11.

25. Dadian T. Dental hygienists' career promotional behaviors and attitudes. J Dent Hyg 1993;67(6):318-25.

26. DeAngelis K, Dean K, Pace C. Career choice and perceptions of dental hygiene students and applicants. J Dent Hyg 2003;77(2):97-104.

27. Monson AL, Cooper BR. Career influences and perception of pre-dental hygiene students. J Dent Hyg 2009;83(3):126-33.

28. Saito A, Tomita C, Sato Y, et al. Perceptions of Japanese and Canadian dental hygiene students toward their profession. Int J Dent Hyg 2009;7:188-95.

29. Hawley NJ, Ditmyer MM, Sandoval VA. Predental students' attitudes toward and perceptions of the dental profession. J Dent Educ 2008;72(12):1458-64.

30. Karibe H, Kawakami T, Suzuki A, et al. Career choice and attitudes toward dental education amongst dental students in Japan and Sweden. Eur J Dent Educ 2009;13:80-6.

31. Rashid H, Manoharan A, Abufanas S, Gallagher JE. Motivation for a career in dentistry: the views of dental students in the United Arab Emirates. Int Dent J 2013;63:259-65.

32. Balasubramanian M, Brennan DS, Spencer AJ, Short SD. The "global interconnectedness" of dentist migration: a qualitative study of the life-stories of international dental graduates in Australia. Health Policy Plan 2015;30: 442-50.

33. Folayan MO, Sofola OO, Khami MR, et al. Study motivates, career choices, and interest in paediatric dentistry among final year dental students in Nigeria. BMC Med Educ 2014;14(130):1-10.

34. Gallagher J, Clarke W, Wilson N. Understanding the motivation: a qualitative study of dental students' choice of professional career. Eur J Dent Educ 2008;12:89-98.

35. Al-Bitar ZB, Sonbol HN, Al-Omari IK. Reasons for choosing dentistry as a career by Arab dental students. Eur J Dent Educ 2008;12:247-51.

36. Aguiar CM, Pessoa MAV, Camara AC, et al. Factors involved in the choice of dentistry as an occupation by Pernambuco dental students in Brazil. J Dent Educ 2009;73(12):1401-7.

37. Yan X, Zhang X, Jinno Y, et al. Career choice and future design of dental students in China and Japan. Int Dent $\mathbf{J}$ 2014;64:68-75.

38. Kobale M, Klaic M, Bavrka G, Vodanovic M. Motivation and career perceptions of dental students at the School of Dental Medicine, University of Zagreb, Croatia. Acta Stomatol Croat 2016;50(3):207-14

39. Khami MR, Murtomaa H, Jafarian M, et al. Study motives and career choices of Iranian dental students. Med Princ Pract 2008;17:221-6.

40. Newton P, Cabot L, Wilson NHF, Gallagher JE. The graduate entry generation: a qualitative study exploring the factors influencing the career expectations and aspirations of a graduating cohort of graduate entry dental students in one London institution. BMC Oral Health 2011;11:25.

41. Rosch (Inglehart) MR, Brown DR. Competition and academic achievement: a longitudinal analysis. Res Med Educ 1988;27:85-90. 